Donald Ipperciel

\title{
Student Centeredness as Innovation
}

\section{The Creation of an AI-Powered Virtual Assistant by and for Students}

\begin{abstract}
:
This article explores how a focus on 'student centeredness' can lead to 'innovation' and how innovation can enhance student centeredness. Putting students at the centre of all considerations can unleash their creative and innovative potential. And recent innovations have made it easier to make students the focal point of service delivery. After a description of what we understand under these two guiding concepts, a case study is presented in which an AI-powered Student Virtual Assistant was developed at York University in Toronto, Canada. All steps of the product creation, including envisioning, designing, prototyping, and evaluating are described, as well as the following steps involving maintenance and expansion.
\end{abstract}

Keywords:

Innovation, Artificial Intelligence, Student Centeredness, Virtual Assistant, Design

\section{Agenda:}

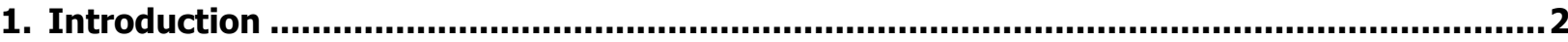

2. Student-Centred Service ............................................................................................

3. Innovation ....................................................................................................................

4. Case-Study: Creating a Student Virtual Assistant at York University..............................4

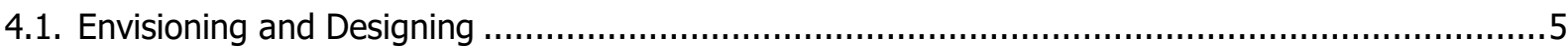

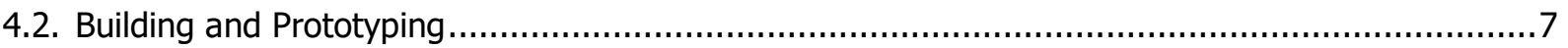

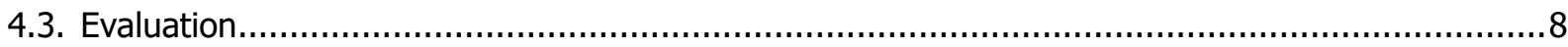

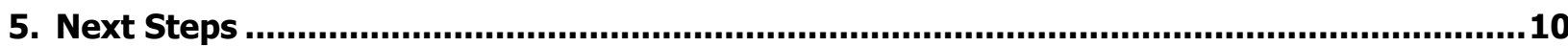

6. Conclusion ....................................................................................................................11

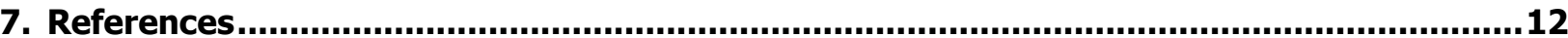

\section{Author:}

Donald Ipperciel:

York University, Toronto Canada

416-736-5257, $₫$ dipper@yorku.ca, 易 https://www.linkedin.com/in/donald-ipperciel-6419499/ 


\section{Introduction}

No one will be surprised to find words such as 'excellence', 'differentiation', 'leadership' or 'student success' in universities' academic or strategic plans. These words belong to the genre, as do 'innovation' and, increasingly, variations on the idea of 'student centeredness'. The latter especially is finding its way into academic parlance, although it is seldom defined and seems to be rather impressionistically understood. To be sure, the idea of student-centred learning has received much attention in the academic literature and rests on a relatively solid theoretical basis, but the notion of student centeredness in the delivery of student services is more nebulous.

Putting students at the centre of our consideration seems straightforward enough, but it is mainly understood in negative terms as not basing service offerings on administrative structures or a purely topdown approach, what is also called being 'institution-focused' (Seifert, 4). But what does it mean in positive and concrete terms? How does one architect a student-centred service?

Innovation, too, is a challenging concept. It is much heralded but often confused with other cognate concepts. Should it be equated with creativity, invention or disruption?

So, when we announce that student centeredness is a means to bring forth innovation, the reader is certainly entitled to further clarification, which will be provided in the following sections. That said, as fruitful definitions may be, nothing clarifies an idea like a concrete example. That is why the theoretical discussion below will be followed by a case study that exemplifies the notion of student centeredness and innovation in the context of higher education. The case study will describe a project in which an AI-powered Student Virtual Assistant was developed at York University in Toronto.

\section{Student-Centred Service}

Student success has become a focal point in the context of changing student demographics and generational expectations. It is also being highlighted in the context of a market-driven view of students as customers. This probably explains the popularity of the new label 'student experience', which echoes the business concepts of 'customer experience' (CX) and to some extent 'user experience' (UX). Classroom interactions are certainly a key dimension of student experience, but so are campus operations, relations with the external community and-most importantly-student support services. Taking on the challenge of student services in higher education institutions is a group of professionals dedicated to supporting students in matters of finance, physical and mental health, counselling, career academic advising, safety, mentorship/coaching, accessibility services, housing, campus life, services for diverse students, and even learning.

Student experience is about taking a holistic view, a key concept in student centeredness. In the past, institutions tended to focus on academics, i.e. classroom experience, assignments and exams, the quality of programs, etc. Taking a holistic view of the student experience, however, means bringing into view the whole journey leading to, surrounding and following the strictly academic experience. In other words, it considers such things as applying to university, forming social relationships, sorting personal finances, finding work, maintaining health and wellness, planning a career path, creating a professional network, making time for family, etc. A student-centered approach considers the whole student.

This approach is not new, but rather has a long and venerable tradition dating back to Athens but generally recognized as an Anglo-American phenomenon (Ciobanu, 170). Take for example this now famous 1937 report from the American Council on Education that defines 'the obligation to consider the student as a whole' as a pillar of higher education (American Council on Education, 68). According to this report, the holistic approach to education was somewhat derailed in the aftermath of the Civil War, as higher education 
institutions turned their focus on academic matters, principally research. As a consequence of the 'pressures upon faculty members to contribute to this growth of knowledge' and their resulting 'neglect of the student as an individual', college administrators recognized the need to appoint 'educational officers' taking on the responsibility of what was termed 'student personnel services', or what we refer today as 'student affairs' or 'student services' (ibid.). And thus was launched the professionalization of student services. Much has been written on the education of the whole student and student experience, among which are classics such as Learning Reconsidered, both volume 1 and 2 (ACPA).

What is new, however, is the level of sophistication that student services have achieved today and the diversity of innovative tools at professionals' disposal. The professionalization of student services over the years has led to various creative approaches that borrow from marketing, service design, customer relationship management, business intelligence, etc. Student service professionals now commonly develop student journey mapping mirroring the student lifecycle, a methodology borrowed from customer service retail and marketing research (Brahme et al., 119). For instance, Lizzio defines five transition phases of the student journey: 'towards (future students), into (commencing students), through (continuing students), up and out (graduates) and back (alumni) to university' (Lizzio; from Roberts). Within the student journey, student professionals identify 'touch points' (i.e. moments of interaction with the institution) to ensure high service standards, as well as 'pain points'. Drawing from the field of marketing (although refined by computer and data scientists), student service professionals also create student personae, i.e. fictional but data-based representations of student types describing typical motivations, limitations, personalities, worldviews, etc. Personae are defined to capture the richness of the target population (in this case students) and ensure that designs and solutions remain concrete.

These tools and methods are called upon in an effort to put oneself in the shoes of the students in all their diversity and to view the university from their perspective. Taking a student-centred perspective is acknowledged as the golden path toward improving service and student engagement.

\section{Innovation}

The movement toward increasing student centeredness is part of a drive for innovation, perceived either as a quest for excellence or a 'survival strategy' in competitive environments (Brown, 7). As with most buzzwords whose meanings tend to erode as they are increasingly used, 'innovation' has come to denote many things to many people. In the ensuing confusion, the word has slipped into slovenly language that does not distinguish between innovation, creation, invention or technology. Certainly, being innovative entails being creative, but artists of all kinds are creative, while only a select few would likely be considered innovative. One major difference is that aesthetics play an important part in creativity, while it is largely unrelated to innovation (Acar). In the media, innovation is often tied to technology, but this is certainly a reduction. One can devise innovative processes, services, business models, forms of engagement, entertainment, etc. (Brown, 7), all of which can be done with old technology. And innovation is not invention. Many new devices and contraptions are inventive, but hardly innovative. It is doubtful that da Vinci's mechanical knight (Moran), Edison's automatic vote recorder (Rutgers), Tesla's oscillator (Wearing) would be considered innovative. It seems that clear attributes are required to qualify as innovation.

Many would associate innovation with disruption, perhaps induced by the recent proliferation of gamechanging technologies such as big data, AI, XR, blockchain, 3D printing, etc. and their phenomenal commercial successes. These striking examples capture our collective imagination. However, at least since Clayton Christensen, we know that innovation need not be 'disruptive' and is often better described as 'sustaining' (Christensen) ${ }^{1}$. Disruptive innovations create a new market and serve previously neglected

\footnotetext{
${ }^{1}$ In the design thinking world, innovation can be incremental (when managing existing users and offering), evolutionary (when growing either new users or new offerings) or revolutionary (when growing both new users and new offerings). See Brown, 2019, 161.
} 
customers, whereas sustaining innovations deliver improvement to pre-existing products or services, whether in small increments or in leaps and bounds (Christensen).

Many commentators have proposed definitions of innovation, too numerous to be listed here. But most share common features, which allows us to suggest the following archetypal definition: Innovation is the implementation of new ideas that creates business value. This compact definition highlights the key elements of innovation:

1. Innovation involves practicality; it is not just about thinking, it is about doing and making.

2. Innovation is about introducing something novel in some context.

3. Innovation fills a need or a want.

4. Innovation generates profits; it is business-relevant.

Unsurprisingly, the common understanding of innovation is skewed toward commercial interests, as the task of defining the term has largely been undertaken by business theorists and practitioners. To better align it with the academic culture, I believe the noun adjunct 'business' can be removed without affecting the essence of 'innovation', which we may simply define as the 'implementation of new ideas that creates value', where 'value' is construed generically as something that matters to people or groups. In this sense, value can be perceived in improved services to students, increased quality of teaching, enriched experience, reduced time spent on administration, etc.

The case can be made that the current pursuit of greater student centeredness is leading to innovation in higher education. As a case in point, let us turn to an innovative project whose goal is foremost to improve student centeredness in a large higher education institution.

\section{Case-Study: Creating a Student Virtual Assistant at York University}

Although innovation need not be technological, technology offers tremendous potential to enhance student centeredness. We know that student satisfaction tends to be inversely proportional to an institution's size. The larger the institution, the lower the satisfaction scores. Intuitively, we understand that a larger studentto-faculty or student-to-staff ratio will result in poorer and often inadequate services. In a context of democratization and massification of universities, technology can be leveraged to provide student-focused personalized services in a wide range of areas. The 'mass personalization' made possible by technology can quickly, efficiently, and consistently handle the many so-called 'transactional' processes in which clients receive discrete services following specific requests. This, in turn, frees up time and resources for more complex relationship-building interactions that require face-to-face interaction. In other words, high tech allows for more high touch. It is in this spirit that a project based in conversational AI technology was undertaken at York University in 2018.

From the inception, the Student Virtual Assistant (SVA) project was conceived as a student-centered project. The project's student centeredness took on many forms, starting with assigning ownership and leadership of the project to the Division of Students. Many other university groups were involved, including the Office of the Provost, University Information Technology (UIT), the Office of Institutional Planning and Analysis, the Registrar's Office, as well as IBM Canada-York's principal partner in the project. Other units were also involved in the process, such as Faculty-specific advising offices. What should be underscored is that it was not the technology that was driving the project, but rather student concerns. UIT and IBM were in this case ancillary to student needs. A multidisciplinary team was created with the goal of understanding students' needs and delivering a solution to meet those needs. 
An early question arose as to where the SVA would reside. New channels could be created for the SVA, but it made more sense to embed it in an environment in which students already spend much of their time. The system students use the most at York University is the Learning Management System (in this case, Moodle). Every single student at York has at least one course per semester on Moodle, so it seemed like a natural environment in which students could interact with the SVA. And because Moodle has a robust mobile application with which students are familiar, the SVA could easily be used on cellphones.

The scope of the project had to be defined. Following previous workshops-which were validated in the envisioning phase-three areas of focus emerged: academic advising, campus life and career development. Clear student-centered outcomes or goals were formulated for each:

Academic Advising: A student can find help if struggling academically, learn about existing tools and services, discover experiential education, and find out where to go for specific academic guidance based on their specific faculty \& program.

Student Life: A student can learn about more ways to get connected and be involved in student life, they can explore university events and become more engaged, they are guided to existing mental health support services.

Career Development: A student can explore career recommendations that are aligned or not aligned to their academic pathway, learn about existing tools to support career exploration and growth, and get advice on finding jobs on and off campus.

\subsection{Envisioning and Designing}

The next steps in the creation of the SVA followed the well-known path of human-centered design (also called 'design thinking'). The team adopted the specific IBM brand of human-centered design as it is presented in the IBM Design Thinking Field Guide (IBM). This approach was a sure way to focus the project on the students' holistic needs and wants. As part of the 'envisioning' phase, which lasted three weeks, three days of enterprise design thinking workshops involving students and staff were launched, each day corresponding to one of the three areas of focus. The first step of human-centered design being about empathizing with stakeholders, the envisioning phase started with identifying pain points in the student's experience at the university. Here's a sample of the pain points gathered during that session:

- Greetings, small talk, questions about Yubie itself

- 'I feel overwhelmed with the process of navigating the resources'.

- 'There is an overload of information, it's hard to clarify what is what, in terms of academic services'.

- 'The main website is not user-friendly'.

- 'There are continuously long line ups to see advisors'.

- 'I am worried if I make the wrong choices at University, how this will have domino effects on my career path'.

- 'I have difficulty in navigating the York University campus due to the size of it'.

- 'There are too many acronyms'.

- 'Not enough events are catered to my interests'.

The design team quickly got a sense of the issues from the students' perspective. The gathered information was organized into 'empathy maps' associated with personae, i.e. typical student types such as the co-op student, the third-year student (sometimes referred to as the 'murky middle'), the mature second-year student, first-year male student, etc., each endowed with specific qualities and attitudes. Each map sorted the information into four categories: what students are saying, what they are thinking, what they do and 
what they are feeling. For instance, the co-op student was saying (among other things) that she had difficulty getting into a class; she was thinking that she did not want to ask for help and was reconsidering her choice of university; she did not attend key classes and academic advising; and she felt confused, anxious and frustrated. 'Big ideas' or solutions were generated from this collection of pain points, both cognitive (e.g. having reminders and alerts for important deadlines) and non-cognitive (e.g. building awareness to improve students' mental health).

In the 'ideation' phase, a solution concept was elaborated based on the data collected at that point. The SVA was given a name and a personality (i.e. a persona) by students, thus projecting their own worldview on it. It was important to humanize the technology, as this speaks to the affective side of the design. Students opted for the gender-neutral name 'Yubie', playing on YU (York University) and the motto 'you be yourself'. In a Likert scale from 1 to 6 , where 1 is 'most appealing' and 6 is 'least appealing', the name 'Yubie scored a 1.9. Similarly, students voted on the icon they preferred for Yubie. They were given the following choices:

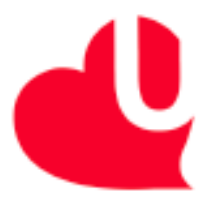

\#1

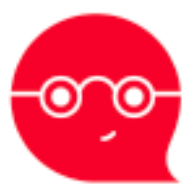

\#2

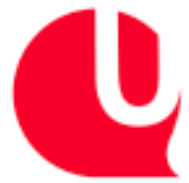

\#3

With the following results:

If I were seeing the Virtual Assistant for the very first time, my preferred icon would be...

\begin{tabular}{|l|l|}
\hline Icon \#1 & $\mathbf{4 3 \%}$ \\
\hline Icon \#2 & $36 \%$ \\
\hline Icon \#3 & $21 \%$ \\
\hline
\end{tabular}

The preferred choice of a friend, shown the same Virtual Assistant logo image, is...

\begin{tabular}{|l|l|}
\hline Icon \#1 & $\mathbf{3 7 \%}$ \\
\hline Icon \#2 & $38 \%$ \\
\hline Icon \#3 & $25 \%$ \\
\hline
\end{tabular}

Students also gave Yubie a biography (e.g. 22 years old, upper-year student, proud Lion, etc.), characteristics (professional, proactive, friendly, etc.), a profile ('Yubie has been around campus for a long time and knows the ropes around York...') and a goal ('to connect students with the right tools and resources to make the most of their York University experience').

Because York University is a bilingual institution, Yubie was trained to respond in both English and French to student queries. In addition, specific outcomes and intents were created and prioritized as a starting point for the build phase. The goal was to have a clear and documented design of student experiences. Finally, a base scope was defined to establish the boundaries of a project that could expand indefinitely. Yubie was now ready to be built for a 'minimum delightful experience'. 


\subsection{Building and Prototyping}

The 'build' phase took 10 weeks and included the app development, the English cognitive training, the English subject-matter expert (SME) testing, the French cognitive training, the French SME testing and the production of an alpha version. This phase was about turning the data gathered from students into a tangible 'product'.

Students were once more called upon in the following 'prototype' or 'pilot' phase, which lasted 12 weeks, and comprised a diverse group of 150 undergraduate students from different campuses, Faculties, and colleges in various years of study. Both student usage data and feedback were used to fine-tune the SVA: the training of the AI was refined based on actual student queries, which improved accuracy and effectiveness; data was collected on what is important to students; and answers were expanded to include select topics that students frequently asked.

By the end of the prototyping phase, Yubie had acquired knowledge, to varying degrees, in the following areas:

\section{General}

- Greetings, small talk, questions about Yubie itself

- Buildings on campus (where to study, reload YU Card, etc.)

- Definitions

- My Courses \& schedule queries

- Special accommodations

- Jokes

\section{Events \& student life}

- Ways to get involved

- Upcoming events (search by date and keywords)

\section{Dates \& deadlines}

- Drop dates, financial deadlines, holiday \& sessional dates

- Pop-up with reminders on key dates

\section{Generic asks for help or advice}

- Asks student to clarify the type of help requested

\section{Academic advice}

- Struggling academically (Learning skill services)

- Switching programs

- Who to talk to depending on specific questions: degree requirements, majors/minors, classes (dynamic based on query \& programs)

- Dropping a course (asks about the 'why')

- Degree progress report (dynamic depending on program)

- Degree requirements (based on program start year)

- Repeating courses

- Withdrawing from courses

- Contacting my professor or TA

- Issues with a professor (dynamic depending on course)

\section{Career}

- Looking for a job

- Professional tips

- Figuring out my interests

- Exploring my career options 


\section{Mental health}

- Feeling lost

- Feeling lonely - do not belong

- Stress, overwhelmed

- Depression, anxiety, sleep issues, etc.

- Potential risk for self-harm or violence

\section{Registrarial services \& financial}

- Contacting registrarial services

- Online services

- Transfer credit queries

- Enrolment letter

- Academic and financial petition queries

- Find my financial status \& financial documents

- Financial aid

- Grade reappraisal

- My Course and grade list

- My recent GPA and academic decision

At this phase, the SVA integrated with systems, including the Student Information System (which provides the student's name, ID, Faculty, campus, college, program, courses, study level, preferred language and status as a domestic or international student) and the interactive campus map. Privacy matters were given full consideration.

\subsection{Evaluation}

The 'evaluation' phase overlapped with the previous phase, as student surveys were conducted during prototyping. Students were asked whether the SVA was helpful in providing information in that week and whether it was enjoyable.

Data was also collected on:

- Weekly frequency of conversation by language

- Total conversations by language

- Number of students who engaged in conversations

- Total feedback received

- Total feedback action required

- Profile of students: gender, study level, Faculty, degree, immigration status, citizenship, language of correspondence, financial aid recipients $(\mathrm{Y} / \mathrm{N})$ and first-generation students $(\mathrm{Y} / \mathrm{N})$

- Top intents mentioned in conversations

Student impressions were also surveyed. With respect to both helpfulness and enjoyability, Yubie improved significantly from beginning to end of the pilot 12 weeks later.

\begin{tabular}{|l|l|l|}
\hline & Helpful & Enjoyable \\
\hline Week 1 & $2.1 / 5$ & $3.1 / 5$ \\
\hline Week 12 (final) & $4.1 / 5$ & $3.0 / 5$ \\
\hline
\end{tabular}

Similarly, the 'net promoter score' (NPS) increased strongly by the end of the prototype phase. Based on the question 'How likely would you be to recommend the Virtual Assistant to a friend or classmate?', Yubie improved from a negative to a positive NPS, with a significant improvement occurring by week 7: 


\begin{tabular}{|l|l|}
\hline & NPS \\
\hline Week 1 & -27 \\
\hline Week 12 (final) & +25 \\
\hline
\end{tabular}

Finally, data was collected on areas that were identified as being the most useful or valuable to students, which provided good insight for future development. Dates and deadlines were considered the most valuable types of information while definitions were perceived as being the least useful.

Qualitative data was also collected with the help of surveys. They provide invaluable, sometimes surprising insights that give meaning to the quantitative data. Consider for instance the following sample based on three survey questions. While one can expect the SVA to make students' lives easier by saving them trips to places of service, the benefits of remaining anonymous when asking delicate questions came as a surprise. As for the negative comments, they mainly point toward areas that should be developed in future iterations of the solution and are as such very useful. However, the most interesting insight is about students feeling they have had a substantial impact in developing a solution they themselves will be using. One feels a sense of pride and ownership in their comments. This is certainly an important takeaway from a project that aimed to be student-centric from the beginning.

\section{Over the course of the pilot, what did you find the most helpful about the Virtual Assistant?}

- 'Yubie was very helpful and it is such a great way for students to get around the smaller obstacles of university'.

- 'It was able to provide me information on the go, without having me visit the office to speak to someone in person'.

- 'How fast it was to get answers and how it suggested questions because there was information I didn't even know was there'.

- 'Yubie's ability to redirect a student to counselling in a non-accusatory manner was really helpful and will help students who need to prioritize certain aspects of their life, especially with such a difficult decision'.

- 'A lot of resources on mental health and academic advising. Students do not know about and make no use of some of the services at York'.

- 'I found the material related to course enrolment the most helpful as it saved me trips to the biology department'.

- 'It gave good general information many university goers are not entirely familiar with or had questions about but never had the chance to ask anyone'.

\section{On the other hand, what did you find the least helpful about the Virtual Assistant?}

- 'Nothing, every single bit of it was helpful'.

- 'Like most AIs, you have to phrase things specifically to get the right information, so I have to rewrite it to get the right info'.

- 'Did not provide dietary needs for food court'.

- 'Least helpful would be that it doesn't really understand about summer courses which is a bummer but I'm sure you guys will fix that... he he...'

- 'Not always able to understand what I'm asking'. 
- 'I found Yubie's inability to answer certain more specific questions other than by sending links to York pages least helpful'.

- 'Not being able to make a calendar of due dates of assignments and not being able to set reminders for them'.

- 'I didn't find the events information to be very substantial, a lot of the times it was sports games and not the types of events I was looking for, like things specific to my major or interests'.

- 'Something Yubie struggles with is recognizing students who are using Yubie to procrastinate. It is very easy to get caught up in the different functionality that Yubie has, and if it has a filter to catch when students have been distracted for far too long (asking for jokes a bunch of times in a row), it would be more realistic and lifelike as well (like an upperclassman gently reminding their younger friend that they need to study)'

\section{Overall, what are your comments and impressions about participating in the Virtual Assistant pilot?}

- 'I am extremely impressed with the guide. I did not think it would be able to answer as many things as it could. I feel that my participation has created an impact because questions I asked at the beginning it could not answer but now it can, so it improved'.

- 'I love participating in it so if you need anyone to participate in another pilot, I am ready. It was so fun to watch it 'grow' into a full virtual guide. I think that my participation may have had a direct impact'.

- ' 'I felt that I helped change the program to help appeal to the francophone population at York'.

- 'I do feel like my participation had a direct impact on the Virtual Guide. [...] Every time I made a comment regarding something Yubie could improve on, it was addressed in just a couple of weeks. Being able to be a part of a group that is shaping something that will be so integral to the student experience is such an amazing opportunity'.

- 'It was really cool being a part of a major milestone of York University and being able to work with York students and IBM. I felt that my participation had a direct impact because when I asked the same question that wasn't answered in the past, the guide would be able to answer it. I felt that I was teaching the guide what resource I wanted it to provide me and potentially another student who may ask the same question'.

- 'It will be a very positive impact on the way students interact. It will help students with social anxiety to find help more easily. It will also save travel to campus for a single question'.

\section{Next Steps}

Conversational AI systems are not meant to be left as-is once they have been created. They must constantly be maintained, trained, improved and expanded to meet user needs. To do so, a permanent team will continue to receive student feedback and analyze usage data to determine areas of improvement. In addition, the institution has planned not only to stay receptive to student expectations, but also to include students in the technical training and improvement of Yubie. The team of developers will include a multidisciplinary group of students (certainly computer science and engineering students but also liberal arts students who can draft conversations in the appropriate style and tone). In the end, Yubie will truly be a solution 'by and for' students. 


\section{Conclusion}

The presentation of a project that sought, from the outset, to understand issues holistically from a student perspective using human-centered design, involve students in all steps of product building and employs students in the maintenance and expansion phase of the development illustrates how a focus on student centeredness can lead to true innovation. In a way, that is what student-centered service is about: having students involved in all steps of the creation process with the goal of providing novel solutions to student issues, whether in the ideation, design, implementation, testing, evaluation or maintenance phase. It corresponds to the shift Tim Brown, the father of design thinking, described: 'from designers creating for people to designers creating with people' (Brown, 59). We often see well-intended initiatives in universities that patently fail, e.g. the 'university app' designed by the technical team, 'libguides' put together with no or little student input, or cleverly designed academic programs that do not meet student needs or wants and are predictably ignored by them. The solution to these failures is simple: ask the students first! Involve them at every step, not just to identify points of 'transactions', but rather considering the end-to-end student experience, both from a cognitive and an affective perspective.

In the end, student centeredness is about more than just putting students at the center of all considerations. It is also letting them speak for themselves-giving them a voice, as some would say. It is acknowledging that they are whole people with emotions in addition to rational purpose. And it is about unleashing their creative and innovative potential. 


\section{References}

Acar, S., 'Ingredients of Creativity: Originality and More"', Creativity Research Journal, 29, 2 (2017), 133144.

American College Personnel Association. "Learning Reconsidered. A Campus-Wide Focus on the Student Experience" (Washington, DC: ACPA, https://www.naspa.org/images/uploads/main/Learning_Reconsidered_Report.pdf.

American College Personnel Association. "Learning Reconsidered 2. Implementing a Campus-Wide Focus on the Student Experience" (Washington, DC: ACPA, 2006), http://nirsa.net/nirsa/wpcontent/uploads/LearningReconsidered2.pdf.

American Council on Education. "The student personnel point of view: A report of a conference on the philosophy and development of student personnel work in colleges and universities" (Washington, DC: 1937), http://www2.bgsu.edu/sahp/pages/1937STUDENTPERSONNELnew.pdf.

Brahme, M. E, Gabriel, L. \& Stenis, P. V., "Don't Stop Believing: Mapping Distance Learners' Research Journeys", Journal of Library \& Information Services in Distance Learning, 10, 3-4 (2016), pp. 118136.

Brown, T., "Change by Design: How Design Thinking Transforms Organizations and Inspires Innovation". New York, NY: Harper Collins, 2009.

Christensen, C., "The Innovator's Dilemma". New York, NY: Harper Collins, 2011.

Christensen, C., Raynor, M. E., McDonald, R., "What is Disruptive Innovation?"' Harvard Business Review, December 2015, 44-53.

Ciobanu, A., "The Role of Student Services in the Improving of Student Experience in Higher Education", Procedia: Social and Behavioral Sciences, 92 (2013), 169-173.

IBM. "IBM Design Thinking Field Guide", version 3.3, ed. Seth Johnson, file:///C:/Users/donal/Desktop/IBM\%20Design\%20Thinking\%20Field\%20Guide\%20v3.3.pdf.

Lizzio, A., "The Student Lifecycle: An integrative framework for guiding practice". Griffith University, 2011. https://www.griffith.edu.au/learning-teaching/ student-success/first-year-experience/studentlifecycle-transition-orientation.

Moran, M. E., "The Da Vinci Robot", Journal of Endourology, 20 (12) (2006), pp. 986-90.

Roberts, J., "Professional Staff Contributions to Student Retention and Success in Higher Education", Journal of Higher Education Policy and Management, 40, 2 (2019), 140-153.

Rutgers, Vote Recorder. Thomas A. "Edison Papers", 2016, http://edison.rutgers.edu/vote.htm.

Seifert, T. A., Arnold, C., Burrow, J., Brown, A., "Supporting Student Success: The Role of Student Services within Ontario's Postsecondary Institutions". Toronto: Higher Education Quality Council of Ontario, 2011.

Wearing, J., "Edison's Concrete Piano: Flying Tanks, Six-Nippled Sheep, Walk-on-Water Shoes and 12 Other Flops from Great Inventors". Toronto: ECW/ORIM, 2009. 